\title{
APONTAMENTOS SOBRE A ECONOMIA DA BORRACHA E A EXPLORAÇÃO DA MÃO DE OBRA INDÍGENA EM RONDÔNIA
}

\author{
Carlos Alexandre Barros Trubiliano (UNIR-carlos.trubiliano@unir.br)
}

\begin{abstract}
RESUMO: A virada do século XIX para o XX foi marcado pela expansão das atividades econômicas na região amazônica, causando profundos impactos socioespaciais. Impulsionado pelas demandadas internacionais da borracha ergueram-se barracões, portos e estradas. Sob a égide do discurso do progresso, milhares de trabalhadores foram cooptados para labutarem na extração do látex. Nos seringais as relações foram marcadas pela violência. Este ensaio apresenta apontamentos sobre a exploração da mão de obra indígena na formação dos seringais em Rondônia. Tratamos sobre as estratégias de cooptação do trabalhador, as condições de trabalho e o contato interétnico. Nosso objetivo foi de contribuir para o debate sobre a expansão das relações capitalistas na região amazônica e os impactos desse processo para as populações indígenas rondonienses.
\end{abstract}

PALAVRAS-CHAVE: Indígena. Seringais. Capitalismo.

\begin{abstract}
The turn of the nineteenth to the twentieth century was marked by the expansion of economic activities in the Amazon region, causing deep socio-spatial impacts. Driven by international rubber demands, sheds, ports and roads were erected. Under the aegis of the progress discourse, thousands of workers were co-opted to labor in the extraction of latex. In the rubber plantations, relations were marked by violence. This essay presents notes on the exploitation of indigenous labor in the formation of rubber plantations in Rondônia. We deal with worker's coping strategies, working conditions and interethnic contact. Our objective was to contribute to the debate about the expansion of capitalist relations in the Amazon region and the impacts of this process on the indigenous populations of Rondônia.
\end{abstract}

KEYWORDS: Indigenous. Seringals. Capitalism.

\section{CONSIDERAÇÕES INICIAIS}

A expansão das relações capitalistas para Rondônia tem sua história marcada pela produção/extração de matéria-prima. É possível dividirmos esquematicamente o desenvolvimento econômico rondoniense em ciclos, com início no primeiro ciclo da borracha no século XIX e mais recentemente, a partir dos anos 1960, o ciclo agropastoril.

O histórico da exploração econômica para região Norte foi marcado pela quase ilimitada distribuição territorial da periferia amazônica, com vistas a desenvolver as atividades de business privado. Diante dos incentivos fiscais e tributários, investidores de capital nacional e internacional foram atraídos para expandirem seus negócios para a região. Desta feita, contando com fartos subsídios oficiais, grupos de investimento, bancos, companhias de seguro, empresas privadas e estatais, mineradoras, cias de transportes e/ou de 
construção de estradas passaram a investir na devastação da floresta, com vistas, a introdução de grandes projetos, nos séculos XVII ao XIX, eminentemente extrativistas e a partir do século XX de produção de commodities, com destaque para criação extensiva de gado e lavoras de soja (KOHLHEPP, 2002).

Esses empreendimentos, ao longo dos séculos foram responsáveis pela destruição de consideráveis extensões de floresta tropical no Norte de Mato Grosso, Centro-Sul de Rondônia, Sudeste e Leste do Pará. Se forcarmos somente em Rondônia, em 1988, o desmatamento atingiu $12,57 \%$ da área total do território rondoniense (IBAMA/CSR, 2011). Os territórios mais afetados localizam-se nas confluências dos municípios de Ariquemes, Pimenta Bueno, Cacoal e Ji-Paraná onde o desmatamento atingiu percentual acima $50 \%$ da área total do município. Rolim de Moura registrou no final da década de 1980 a marca de 74,5\% de desmatamento da extensão total do município (SEDAM, 2002). Hoje (2017) o Estado de Rondônia já desmatou mais de $50 \%$ de suas florestas.

Segundo dados do Instituto Nacional de Pesquisas Espaciais (INPE/2017), no ano de 2016, Rondônia foi o Estado brasileiro que apresentou o maior índice de desmatamento com $30 \%$ de desmate da floresta, seguidos por Mato Grosso 28\%, Pará 21\% e Amazonas 20\%. Das áreas devastadas, as de natureza jurídicas privadas e devolutas foram responsáveis por mais da metade da degradação com $63 \%$, seguido pelas unidades de conservação com $30 \%$, os assentamentos de reforma agrária em 5\% e as Terras Indígenas com menos de 1\%, o que reforça a tese que as Terras Indígenas tem servido como uma "barreira" para frear o avanço do desmatamento.

Para nosso artigo iremos nos ater aos ciclos da Borracha que ocorreu em dois momentos, o primeiro, por volta de 1877, se insere no final do "boom" da produção da borracha amazônica, momento em que a região Norte foi o maior polo de extração e exportação de látex do mundo, chegando a produzir, em seu auge, 2.673 toneladas de borracha/ano. O segundo momento, teve início em 1942, motivado pelas demandas da indústria bélica da segunda guerra mundial. A produção da borracha promoveu o deslocamento migracional, especialmente de nordestinos, para o vale do Madeira e seus afluentes: rios Machado, Mamoré, Guaporé e Jamari (FONSECA \& TEIXEIRA, 2003).

Para compreendermos a relação do desenvolvimento da economia da borracha e a exploração da força de trabalho indígena dividimos esse ensaio em duas partes, na primeira discutimos o imaginário burguês da virada do século XIX para XX, que considerou o 
indígena como uma barreira a civilização, portanto a ser "domado" em nome do progresso; diante desse imaginário, discutimos a consolidação da economia da borracha no território rondoniense, que explorou de maneira compulsória a mão de obra indígena, tratando-a como um dado da natureza, portanto, um elemento a ser explorado.

\section{O ÍNDIO E A NATUREZA COMO BARREIRA PARA O PROGRESSO NO IMAGINÁRIO BURGUÊS}

A mentalidade do homem ocidental, desde fins do século XIX e ao longo de todo o século XX, teve como marca a "utopia do progresso", ideário que foi elemento constitutivo das políticas e práticas as quais nortearam as ações dos Estados e das pessoas comuns. A crença na técnica, materializada especialmente nas "artes mecânicas" e na indústria - ambas resultantes dos avanços dos conhecimentos científicos -, representava o domínio do homem sobre a natureza.

A convicção de que, nos saberes da ciência, residia o fundamento do progresso e, neste, a condição para a felicidade e o bem-estar da humanidade surgiu no Ocidente, com o aval dos Estados Nacionais - um projeto político-pedagógico centrado em ciência e tecnologia, cuja perspectiva era a "reinvenção" da sociedade por meio das máquinas. Diante desta capacidade técnica e das ambições de recriar o mundo de acordo com as pretensões e necessidades da burguesia, grupo social detentor de capitais e recursos tecnológicos, todo o século $\mathrm{XX}$ foi marcado pela remodelação do espaço e do tempo.

Caberia à ciência, por meio da técnica e do progresso, transpor os obstáculos impostos pela natureza. Desta forma, ergueram-se "obras como túneis gigantescos, pontes e viadutos monumentais, canais, represas, complexos industriais, linhas férreas e outras (...) por todos os lugares, mesmo naqueles que antes pareciam inacessíveis" (CASTRO, 1993: 20); essas construções atestavam a capacidade ilimitada do homem e demonstravam os anseios da burguesia em imprimir marcas duradouras na sociedade.

Paulatinamente, as nações perceberam as potencialidades da ciência para $o$ desenvolvimento de seus impérios, investindo em sua produção. Tais políticas criaram, além dos avanços tecnológicos, a percepção de que somente por meio do progresso era possível alcançar o status de "civilização", distanciando-se da "barbárie". Segundo Hobsbawm, o Ocidente, já em finais do século XIX, apresentava-se cada vez mais globalizante, “cujo ritmo 
era determinado por seu núcleo capitalista desenvolvido ou em desenvolvimento se transformasse num mundo onde os 'avançados' dominariam os 'atrasados'; em suma, num mundo de império" (HOBSBAWM, 1998: 89). Diante dessa concepção, os impérios justificavam sua dominação tanto para os dominados quanto para os dominantes.

Edward W. Said (1995) chama a atenção para os elementos discursivos, um dos principais mecanismos imperialistas para legitimar a dominação. Ao utilizar o silogismo do dever "civilizacional", o sistema ideológico ocidental estabelece um enorme fosso entre o Ocidente civilizado, com seu tradicional compromisso "com a dignidade humana, a liberdade e a autodeterminação, e a brutalidade bárbara daqueles que, por alguma razão - talvez genes defeituosos -, não conseguem apreciar a profundidade desse compromisso histórico" (SAID, 1995: 351).

Se pensarmos no discurso imperialista, apontado por Said e Hobsbawm, o conceito de civilização aparece como elemento que norteia a justificativa da expansão e da dominação dos impérios, cujos alicerces estão atrelados a um conjunto de elementos políticos, religiosos, técnicos, sociais e morais que determinariam, em última instância, os pressupostos teóricos que formariam o processo civilizador do Ocidente.

Neste sentido, a análise de Norbert Elias (1994) evidencia de que maneira diferentes situações históricas, tradições e processos políticos de formação dos Estados - bem como da ascensão da burguesia francesa e alemã, durante o século XIX - criaram elementos para identificar a ideia de civilização e "a consciência que o Ocidente tem de si mesmo: tudo aquilo em que a sociedade ocidental (...) se julga superior a sociedades mais antigas ou a sociedades contemporâneas mais primitivas” (ELIAS, 1994: 64). Essa consciência justificou as pretensões imperialistas, empreendimentos expansionistas e de colonização de outros povos - processo amplamente denunciado nas obras de Said.

Logo, essa "consciência da superioridade de seu próprio comportamento e sua corporificarão na ciência, tecnologia ou arte começariam a se espraiar por todas as nações do Ocidente" (ELIAS, 1994: 64). Na esteira da segunda Revolução Industrial e da hegemonia política e econômica dos países industrializados da Europa, o processo civilizatório e de dominação dos "incivilizados", norteado pelo ideário liberal burguês de "progresso", era legitimado pelo discurso político. Para Hobsbawm, esse processo, na América Latina, "tomou o caminho da 'ocidentalização' na sua forma burguesa liberal com grande zelo e 
ocasionalmente grande brutalidade, de uma forma mais virtual que qualquer outra região do mundo, com exceção do Japão" (HOBSBAWM, 1998: 144).

A produção historiográfica contemporânea entende que a expansão imperialista, na passagem do século XIX para o XX, foi marcada pela afirmação das nacionalidades como ideologia justificadora e impulsionadora da conquista e da dominação de outros espaços e povos. Hobsbawm, como exemplo da ideia anterior, considera França, Inglaterra, Bélgica e Alemanha como nações mobilizadas para a missão "progressista" de "civilizar" o "outro geográfico", em territórios para além das fronteiras do Estado Nacional (HOBSBAWM, 1998).

No caso dos países da América Latina, recém-saídos da condição de colônia, a conquista e a dominação do "outro geográfico" não eram compreendidas como a culminância da ação civilizatória, mas como etapas deste processo, confundindo-se com o projeto da própria constituição da nação (PIZARRO, 1994).

Antes de tratar do caso brasileiro e, mais especificamente, o de Rondônia, é válido apontar o processo de conquista do $\mathrm{Chaco}^{2}$ e sua relação com a elaboração do discurso identitário e nacionalista argentino. As expedições militares, denominadas Campaña del Desierto (1879-1884), buscaram colonizar o Chaco argentino e civilizar seus habitantes, "los chaqueños". A região era constituída, majoritariamente, por indígenas ${ }^{3}$; era, portanto, "el otro cultural". Para a jovem nação argentina, era necessário eliminar "la imagen de la barbarie, del Desierto, de las fronteras interiores, en síntesis (o Chaco e seus habitantes) representaban un problema serio para el Estado-nación en conformación" (LAGOS, 2000: 69) ${ }^{4}$.

O que se sucedeu no Chaco argentino após a Campaña del Desierto foram empreendimentos de cunho civilizacional, como a construção de ferrovias, telégrafos e estradas e as políticas de incentivo à migração interna ou estrangeira, materializadas em

\footnotetext{
${ }^{1}$ A ideia de "outro geográfico" é compreendida como uma relação de alteridade que nos define por ser aquilo que não somos - ou não queremos ser. No caso em questão, esse "outro geográfico" representa o mundo não europeu, que cumpriu importante função na cristalização da consciência nacional, uma vez que, através do contraste cultural, político e, principalmente, econômico, afirmava a noção de superioridade das potências europeias, bem como de seus cidadãos frente ao novo mundo. Para mais informações sobre o conceito de "outro geográfico", ver Moraes, 2003.

${ }^{2} \mathrm{O}$ Chaco é uma área de, aproximadamente, $1.066 .000 \mathrm{~km}^{2}$ de extensão, localizada nos limites territoriais de Argentina, Paraguai, Bolívia e Brasil (RENSHAW, 2006).

${ }^{3}$ As maiores etnias do Chaco são os Ayoreos, Tobas, Pilagás, Guarani e Matacos (POLANCO, 1995).

${ }^{4}$ Para uma perspectiva geoantropológica da ocupação do Chaco, é possível consultar a pesquisa de Pablo G. Wright (1997), "El desierto del Chaco: geografías de la alteridad y el estado". Quanto aos conflitos gerados pela inserção dos empreendimentos capitalistas na região, podemos citar o trabalho de Nicolás Iñigo Carrera (1988), "La violencia como potencia económica: Chaco 1870-1940".
} 
campanhas de povoamento e colonização. Tais iniciativas representavam não apenas o progresso material, de expansão de fronteiras e ocupação dos espaços, mas a concretização de um projeto mais amplo: a construção da nação civilizada.

É possível afirmar que cenário similar se apresentava no Brasil. A partir de meados do século XIX, parcela significativa de intelectuais e dirigentes políticos identificou nos sertões uma fronteira entre civilização e barbárie dentro do próprio território nacional; julgou-se necessário superar as contradições para que se concretizasse o projeto do Estado-Nação progressista e civilizado (SOUZA, 1997). Essas elites elaboraram uma retórica civilizacional, comprometida com a ocupação das áreas ditas "vazias", ou seja, espaços ainda não submetidos completamente ao controle do Estado e à dinâmica econômica capitalista e que, quase sempre, eram habitados por populações consideradas "selvagens" ou pouco civilizadas. "Dominar", "colonizar", "civilizar" esses "desertos" e seus "bárbaros" habitantes tornavamse, portanto, ações nacionalistas.

Nesse contexto, já no período republicano, o Estado brasileiro adotou algumas medidas, como a expansão de unidades militares, a construção das Linhas Telegráficas e de ferrovias, como a Madeira-Mamoré e a Noroeste do Brasil - consideradas, pela elite política brasileira do início do século XX, obras civilizacionais capazes de integrar a nação e levar o progresso ao interior do país.

Essas iniciativas são expressões do ideário liberal burguês de civilização e visavam acompanhar o desenvolvimento econômico das nações de capitalismo mais desenvolvido. Parcela significativa dos dirigentes políticos e intelectuais brasileiros tendeu a dirigir-se pela perspectiva de que era imperativo sintonizar o Brasil com os avanços do mundo moderno, inserindo-o na marcha da história rumo ao progresso. Estava em curso, então, o que Hobsbawm denominou a "conquista do globo pelas imagens, idéias e aspirações (...) tanto pela força e pelas instituições como por meio do exemplo e da transformação social" (HOBSBAWM, 1998: 114). Para a maior parte da elite política nacional, isso significava promover, na sociedade, a implantação de um modelo de desenvolvimento econômico, político e cultural que a aproximasse do perfil dos países industrializados do Ocidente.

Nesse contexto, instaurou-se como procedimento intelectual a constituição de um "outro geográfico" sobre territórios e populações à margem da modernização capitalista. Nessa relação de alteridades, as populações indígenas foram compreendidas como obstáculos a serem superados pelo progresso. 
A percepção de "domesticar" a natureza conforme os propósitos da civilização transformando territórios incultos em áreas de cultivo ou cidades, como medida de progresso - está presente, por exemplo, na obra de Augusto Comte. Em sua análise sobre a "dinâmica social”, o autor atribui à condensação populacional num dado espaço um dos fatores primordiais para o estabelecimento do progresso e da civilização (COMTE, 1978).

No final do século XIX, teorias como o evolucionismo social, o positivismo, o naturalismo e o darwinismo social exerciam forte influência nos homens da ciência e do Estado. Para Lília M. Schwarcz (1993), a "sciencia" que chega ao Brasil no final do século XIX não era de caráter experimental, mas sim um modelo evolucionista e social-darwinista, originalmente popularizado enquanto justificativa para a ação imperialista de dominação.

O contraste entre a vastidão territorial rondoniense e sua pequena população, bem como a constatação de que a maior parte deste espaço era desabitada ou habitada por povos indígenas foram determinantes para estabelecer a representação de Rondônia como um deserto selvagem e inóspito.

\section{O SISTEMA DE BARRACÃO E A FORMAÇÃO DOS SERINGAIS EM RONDÔNIA}

\section{DIÁSPORA}

Para iniciarmos esse ponto do artigo, é preciso chamar a atenção dos leitores para o fato de que o Código Penal brasileiro de 1940, em seu artigo 149, já previa a criminalização do trabalho análogo à escravidão; a pena prescrita aos infratores era reclusão, de dois a oito anos. O Código Penal passou por inúmeras e importantes revisões ao longo do tempo; em 1940, por exemplo, não estava claro na redação da lei a definição de trabalho análogo à escravidão. Somente na revisão feita em 2003 é que se definiu que reduzir alguém à condição análoga à de escravo é submetê-lo "a trabalhos forçados ou à jornada exaustiva, quer sujeitando-o a condições degradantes de trabalho, quer restringindo, por qualquer meio, sua locomoção em razão de dívida contraída com o empregador ou preposto" (BRASIL, 2003, [s.p.]). A nova redação do artigo 149 recebeu elogios da Organização Internacional do Trabalho (OIT) e críticas de setores ligados ao agronegócio, os quais, através de sua bancada legislativa, tentam revisar a lei. 
O que se segue, a partir deste ponto, são exemplos, histórias e memórias da exploração a que trabalhadores, especialmente indígenas, estiveram submetidos nos seringais de Rondônia. Os impactos dessa exploração foram nefastos às culturas dos povos da floresta, que sentem até os dias atuais os efeitos do desenraizamento e do etnocídio. A mobilização de setores conservadores da sociedade brasileira - sobretudo o do agronegócio - para “flexibilizar" a redação e, portanto, a noção de trabalho análogo à escravidão revela que esse tipo de exploração laboral ainda existe e o quanto precisamos avançar na luta para garantir que a democracia, no Brasil, deixe de ser um "lamentável mal entendido" (HOLANDA, 1991: 160).

Em relação ao ciclo da borracha, sua origem está ligada às descobertas de Charles Goodyear - que, em 1840, desenvolveu o processo de vulcanização da borracha, deixando-a mais resistente e propícia para uso industrial. A descoberta fez com que a demanda do látex in natura crescesse exponencialmente. A região amazônica, então maior zona produtora de látex do mundo, transformou-se na maior exportadora do produto. Para que tenhamos uma ideia, entre os anos de 1830 e 1860, a exportação do látex amazônico saltou de 156 para 2.673 toneladas/ano; em 1910, o Brasil chega ao ápice de produção e exportação com, aproximadamente, 40 mil toneladas do produto.

No que diz respeito à instalação de infraestrutura, o governo brasileiro não assumiu diretamente o financiamento para organizar a produção do látex; ao Estado, interessavam mais os impostos sobre a exportação. Deste modo, ficou a cargo do capital internacional constituir a atividade extrativista, seja na forma de crédito para as exportações e importações ou na forma de empréstimos aos governos locais. Houve um cenário ideal para a corporificação do capital monopolista na economia gomífera amazônica; em outros termos, quem determinou os cursos da economia extrativista da borracha foram os principais parques industriais britânicos e estadunidenses.

O desenvolvimento da economia da borracha provocou profundas transformações socioambientais na região amazônica. Segundo Itamar Souza (1978), no período de 1890 até 1910, o contingente migracional para a Amazônia teria sido de, aproximadamente, meio milhão de pessoas, em sua maioria oriundas da Região Nordeste do Brasil.

A migração de nordestinos para o Norte recebeu incentivos estatais, inicialmente, em forma de propaganda e outros atrativos, como passagens e alimentação; posteriormente, a migração passou a ser compulsória. Segundo João Medeiros Filho e Itamar Souza (1984), 
mesmo aqueles que não desejavam migrar eram obrigados pelo Estado, que se utilizava do monopólio da força. O ápice da política migracional para a Amazônia aconteceu em 1943, com a criação do Serviço Especial de Mobilização de Trabalhadores para a Amazônia (SEMTA): no seu primeiro ano de atuação, mais de 60 mil trabalhadores foram enviados para trabalhar nos seringais.

Entretanto, mesmo com tamanho deslocamento populacional, a demanda por mão de obra nos seringais não foi suprida. Diante disso, as companhias passaram a pressionar os governos locais para mobilizar e utilizar força de trabalho indígena, provocando o deslocamento de aldeias e mesmo de nações indígenas inteiras para atender à demanda dos seringais. Em Rondônia, como exemplo, podemos citar a migração forçada dos Kanoê, Arikapú e Djeoromitxí.

Originalmente, o povo Kanoê habitava a margem esquerda do Rio Pimenta Bueno (RO) e as cabeceiras do Rio Guaporé (RO); estas áreas eram pouco acessíveis até o início do século XX, fazendo com que este grupo étnico vivesse, essencialmente, isolado. Em 1909, a expedição das Linhas Telegráficas Estratégicas do Mato Grosso ao Amazonas (Comissão Rondon), ao adentrar a região dos Rios Pimenta Bueno e Corumbiara, passou a estabelecer contato com os Kanoê (MALDI, 1984). Em 1943, o coronel Aluísio Pinheiro Ferreira, então governador do Território Federal do Guaporé, determinou o deslocamento dos Kanoê para o Posto Indígena Ricardo Franco (atualmente, P.I. Guaporé). De acordo com as pesquisas de Denise Maldi (1984; 1991), os índios foram transferidos para suprir as baixas dos trabalhadores acometidos por epidemias de sarampo e gripe. O Posto Indígena não contava com infraestrutura para atender aos recém-chegados; sem a possibilidade de formação das roças, coube aos Kanoê trabalhar em tempo integral na produção da borracha em troca de alimentos. Em pouco tempo, contraíram as mesmas moléstias que haviam vitimado os seringueiros; a mortalidade entre os Kanoê foi tão alta a ponto de quase serem extintos.

O ciclo da borracha também deixou marcas na história do povo Arikapú. Originalmente, eles viviam à margem direita do Rio Guaporé (RO), tendo contato regular com os não indígenas desde o fim do século XIX (CASPAR, 1958). Na década de 1920, os Arikapú foram empregados na extração de látex, castanha do Pará e ipeca. Nos "barracões" dos Rios Branco, Colorado, Mekens e Corumbiara, trabalhavam em troca de alimentos, facões e machados de metal. Na década de 1930, o Serviço de Proteção ao Índio (SPI) passou a transferir grupos indígenas Arikapú do sudoeste de Rondônia para colônias agrícolas e 
seringais na região oeste, na confluência entre os Rios Guaporé e Madeira. Nas colônias, os Arikapú passaram a trabalhar em regime análogo à escravidão (MALDI, 1984). Segundo o etnolinguista Hein van der Voort (2007), muitos tentaram fugir e regressar a suas terras de origem ou para a cidade de Guajará-Mirim, à época capital do Território Federal do Guaporé; porém, quando capturados, eram enviados para trabalhos forçados no Posto Indígena Ricardo Franco.

Assim como os Arikapú e os Kanoê, o povo Djeoromitxí também sofreu o processo de migração forçada para colônias de trabalho. Segundo Franz Caspar (1975), até a década de 1950, os Djeoromitxí habitavam a margem esquerda do Rio Branco, próximo ao atual município de Alta Floresta d'Oeste (RO). Maldi (1991) estima que, antes do contato com os não indígenas, sua população alcançava os milhares de indivíduos que habitavam grandes malocas em formato de colmeia; sua subsistência se baseava em coleta de frutas e insetos, pesca, caça e agricultura de roçado. No primeiro quartel do século $\mathrm{XX}$, surgiram às margens dos Rios Branco, Mekens, Colorado e Corumbiara barracões de "caucho" (borracha). Nos barracões, os não índios passaram a atrair grupos indígenas, ofertando-lhes machados e facões de metal; o povo Djeoromitxí, assim como outras etnias, estabeleceu uma relação de troca nos barracões. Por volta de 1920, os Djeoromitxí passam a ser empregados no seringal Paulo Saldanha, na cabeceira do Rio Branco; em 1934, este seringal foi foco irradiador de uma epidemia de sarampo, que se alastrou por toda região. Fugindo da epidemia, os Djeoromitxí desceram o Rio Branco até o seringal São Luis, onde se encontravam, também, muitos Aruá, Makuráp e Wayurú. Na medida em que o seringal São Luis apresentava “excedente de mão de obra”, o Estado passou a recrutar e encaminhar os Djeoromitxí - bem como outras etnias para colônias de trabalho (CASPAR, 1975; MALDI, 1991).

Diante do contato e do histórico de exploração e diáspora, os Kanoê, Arikapú e Djeoromitxí passaram a viver nas T.I. Rio Branco e T.I. Rio Guaporé. Apesar de morarem em territórios demarcados e homologados - logo, em tese, áreas protegidas -, esses grupos ainda estão à mercê do desenvolvimento predatório. A ação de madeireiros, pescadores comerciais e mineradores de cascalho e o uso de pesticidas nas lavouras das fazendas vizinhas coloca em risco a existência desses povos; mais recentemente os projetos hidrelétricos, como as várias Pequenas Centrais Hidrelétricas (PCHs) construídas na bacia do Rio Branco, vêm causando profundos impactos nessas comunidades. 


\section{OS BARRACÕES}

Embora o ciclo da borracha seja propagado como um período áureo, na prática, a Região Norte não enriqueceu; ainda que cidades como Belém e Manaus tenham se desenvolvido, o fato é que os capitais excedentes se localizaram nas pontas do sistema, ou seja, na Europa e nos EUA. Exemplificando tal situação, em 1943, o International Rubber Regulation Committee estimou o quilo da borracha no valor de um dólar; em contrapartida, segundo o Relatório do Instituto Agronômico do Norte (26/12/1943), eram pagos nos seringais dois cruzeiros por quilo, sendo que "o rendimento bruto dos pequenos seringais não atinge sequer 800 cruzeiros, em média, por ano" (CAMARGO, 1943: 05). Para dimensionar os valores mencionados, o Decreto-Lei $\mathrm{n}^{\circ} 5.977$, de 10 de novembro de 1943, estipulou o salário mínimo em Cr\$380,00 para o ano de 1944; ou seja, o trabalhador assalariado (geralmente, urbano) recebeu um soldo diário de Cr\$12,66. Outros dados importantes, segundo o Instituto Agronômico do Paraná (2000): uma seringueira produz, em média, 50 gramas de seiva por dia; um seringueiro consegue produzir, no máximo, $400 \mathrm{~kg}$ de borracha por ano. Se cruzarmos esses dados, em 1943, um seringueiro que recebesse Cr\$2,00 por quilo de borracha (sendo que este era o preço pago ao dono do seringal) conseguiria, ao final do ano, uma receita de Cr\$ 800,00; com esse valor dividido por 12 meses, o seringueiro teria um salário mensal de, no máximo, $\operatorname{Cr} \$ 66,00$, ou um soldo diário de $\operatorname{Cr} \$ 2,20$. Diante desses valores, não é difícil imaginar a situação de miséria entre os trabalhadores, sejam eles da seringa ou de atividades ligadas indiretamente à economia da borracha.

Perante o exposto, o sistema de barracão pautava as relações empregatícias, condicionando os trabalhadores a um regime análogo à escravidão. A utilização dos armazéns ou das "vendas", que forneciam gêneros alimentícios e equipamentos de trabalho, foi prática comum em construções, fazendas, seringais e minas em regiões isoladas.

O sistema de exploração nos seringais foi pensado esquematicamente por João Pacheco de Oliveira Filho (1979), que identificou dois modelos: o caboclo e o do apogeu. No modelo caboclo, mais comum no início da exploração da borracha (início do século XIX), o produtor gozava de relativa independência em relação ao dono do armazém (barracão), uma vez que executava atividades diversificadas, complementando a renda extrativista com cultivo e criação - ou seja, sua subsistência não estava estritamente ligada à aquisição de produtos no armazém, o que permitia ao trabalhador uma relativa autonomia produtiva e certo controle 
sobre seus débitos. Essa força de trabalho era formada, geralmente, por trabalhadores indígenas e retirantes nordestinos.

O modelo apogeu, mais recorrente no final do século XIX e início do XX, foi marcado pelo acentuado controle da força de trabalho. O trabalhador passou a ser submetido a labutar, exclusivamente, na atividade extrativista, e não dispunha de condições para exercer atividades complementares de subsistência, tornando-se dependente dos produtos fornecidos pelo barracão. A força de trabalho nesse modelo também foi formada, majoritariamente, por indígenas e retirantes nordestinos; contudo, seu recrutamento se insere num contexto de coerção - muitas vezes, foram enviados para regiões remotas; o isolamento e o policiamento exercido pelos jagunços são elementos que nos ajudam a compreender o controle sobre o trabalhador.

Ao monopolizar o potencial de compra dos empregados por meio do fornecimento de crédito e da manipulação dos valores, os empregadores condicionavam os trabalhadores "a uma dívida impagável, lançando em suas cadernetas saldos negativos, forçando-os a permanecer no trabalho até a possível e improvável quitação do débito” (MARTINS, 1979: 98). Quanto às formações dos barracões em Rondônia, destacamos os casos dos Kaxarari, Arara e Negarotê.

Atualmente, a terra indígena Kaxarari está localizada nas cercanias dos distritos de Califórnia (RO) e Extrema (RO), divisas de Rondônia, Acre e Amazonas. Originalmente, os Kaxarari estavam na cabeceira do Igarapé Curequeté, afluente da margem direita do Rio Ituxy. Os dados mais atuais do Sistema de Informação da Atenção à Saúde Indígena, gerenciado pela Secretaria Especial de Saúde Indígena (SIASI/SESAI), são de 2014 - e informam que a população dos Kaxarari é de 350 indivíduos; no século XIX, eram estimados em, aproximadamente, dois mil índios (AQUINO, 1985).

A formação dos barracões gerou impactos profundos na etnia Kaxarari, a ponto de ser o elemento norteador da memória desse povo. A partir do contato com os seringalistas, os Kaxarari narram a sua história, contada a partir de três momentos, ou tempos, como eles próprios definem. São eles o "tempo das correrias", o "tempo do cativeiro" e o "tempo dos direitos".

O "tempo das correrias" data do início do século XX, quando seringalistas brasileiros e peruanos promoveram expedições - as chamadas "correrias" - com intenção de expropriar as terras dos índios, ricas em seringa e castanha. Essas expedições foram marcadas pela extrema 
violência, segundo Cristina WOLLFF (1999); seus objetivos principais eram o assassinato dos homens e a captura das meninas, mulheres e crianças pequenas, as quais eram vendidas entre os seringueiros e comerciantes locais.

Por volta de 1940, após o processo de etnocídio e a expropriação das terras dos Kaxarari, os seringalistas procuraram "amansar" os sobreviventes para utilizá-los como força de trabalho; iniciava-se o "tempo do cativeiro". Os Kaxarari passaram a ser incorporados ao sistema de barracão, permanecendo atrelados a uma dívida impagável no armazém. $\mathrm{O}$ "tempo do cativeiro" estende-se até fins da década de 1960, momento em que coincidem a decadência dos seringais e a construção do trecho da BR-364 que liga Porto Velho (RO) a Rio Branco (AC); a estrada passa nas proximidades das aldeias Kaxarari, o que lhes permitiu o deslocamento das cabeceiras dos Rios Curequeté e Ituxy para a margem esquerda do Rio Azul, área de pouca influência dos seringalistas. A rodovia também possibilitou aos Kaxarari a comercialização de seus produtos com pequenos intermediadores, chamados de "marreteiros da estrada". Entretanto, é preciso destacar que a relação comercial entre os Kaxarari e os "marreteiros" continuou desigual, uma vez que os comerciantes superfaturavam mercadorias industrializadas e desvalorizavam a produção dos indígenas (SANTOS, 2002).

Somente em meados da década de 1970, com a instalação de uma "Ajudância" da Fundação Nacional do Índio (FUNAI) no Acre, os Kaxarari passaram a ter ciência de seus direitos; iniciava-se o "tempo dos direitos". Em 1978, foram feitos os primeiros estudos topográficos para demarcar as terras dos Kaxarari, provocando uma longa disputa política e judicial - que se arrastou até 1991, quando são finalmente demarcadas e homologadas as T.I. do povo Kaxarari (FUNAI, 1997).

Como podemos constatar, de modo a atender à demanda por látex, os seringais estabeleceram barracões como forma de intermediar a exploração sistemática da força de trabalho indígena, a exemplo dos Kaxarari e de outras etnias. Entretanto, segundo Edinéia Izidoro, as relações entre as diversas etnias e os seringalistas foram pautadas não apenas pelo conflito, mas também pela dependência. A expansão dos seringais impôs aos povos indígenas uma nova forma de vida, notadamente marcada por trabalho semiescravo e doenças - mas, também, por novos hábitos, uma vez que, após o contato, passaram a ter novas necessidades, como o uso de remédios e o consumo de alimentos até então desconhecidos, como arroz, café e açúcar (IZIDORO, 2006). 
A compreensão das relações que sucedem aos contatos interétnicos é bastante complexa. Muitas vezes, a figura do colonizador/conquistador é retratada de forma dúbia: não raro, um grupo social ou comunidade emite representações conflitantes de determinado indivíduo ou de outro grupo social. Indivíduos que ora são representados como "devastadores", "assassinos" e "exploradores" também são concebidos como "protetores", "benfeitores" ou mesmo "paternos". Como exemplo, destacamos a relação entre o seringalista conhecido como "Barros" e a etnia Arara.

Edilson Medeiros Filho (2003) informa que, possivelmente, os primeiros contatos dos Arara com os não índios ocorreram por meio de garimpeiros e missionários, no fim do século XIX - mas foram intensificados com a expansão das Linhas Telegráficas e o desenvolvimento da extração de seringa. Em meados da década de 1940, na região do atual município do Jiparaná (RO), surgiram os primeiros seringais e barracões próximos às aldeias dos Arara; neste contexto, destaca-se a figura de "Barros".

Segundo a bibliografia consultada (MEDEIROS FILHO, 2003; IZIDORO, 2006; NEVES, 2006), coube ao seringalista "Barros" a primazia no processo de aliciamento da força de trabalho dos Arara. Para compreender o sucesso dessa empreitada, ressaltam-se dois elementos; o primeiro relaciona-se ao fascínio despertado nos índios pelos produtos industrializados - devido à novidade ou à praticidade trazida às tarefas do dia a dia, a exemplo de facões, enxadas e foices, utilizados na lida das roças -; o segundo elemento tem natureza política: o período em que os seringais se estabeleceram na região coincidiu com os conflitos interétnicos entre os povos Arara, Gavião e os Uruku, ou Urubu - os últimos liquidados pelos ataques dos Arara e dos seringalistas. Os conflitos geraram um cenário favorável aos seringalistas, que souberam potencializar as disputas, enfraquecendo as resistências das etnias e ampliando os elos de dependência dos indígenas com os barracões. Em poucos anos, a maioria dos índios da região de Ji-Paraná havia se tornado força de trabalho da cadeia produtiva da borracha.

Dessa forma, os Arara foram distribuídos para trabalhar em diversos seringais da região; a maioria jamais retornou à sua aldeia. Muitas crianças foram "adotadas" pelas famílias dos seringalistas, como forma de "aculturação"; o resultado desse processo é a relação de conflito e dependência desenvolvida entre os Arara e os seringalistas. Na memória de alguns Arara, "Barros", ainda hoje, é considerado um "protetor", tanto dos outros seringalistas quanto das tradicionais etnias inimigas. 
O histórico da relação entre os Arara e os seringalistas promoveu um clima de desconfiança entre os Arara e os Gavião que ultrapassou o tempo dos seringais. Contemporaneamente, persiste o mal-estar entre os anciãos Arara e Gavião; contudo, as novas gerações - especialmente aqueles que seguiram carreira no magistério indígena - têm se esforçado para estabelecer um laço de fraternidade entre as duas etnias, vital para a resistência indígena diante do atual estágio das frentes de expansão capitalistas, as quais ameaçam a integridade física e social desses povos.

A formação dos barracões também é um componente fundamental para a formação da memória étnica dos povos indígenas. Conforme Michel Wieviorka (2004), as memórias das tragédias, muitas vezes, transformam-se em memórias de afirmação; nessa operação, o coletivo converte as lembranças e o reconhecimento de seus sofrimentos em elementos de integração. Nesse sentido, podemos destacar a importância da memória do episódio conhecido como "Barracão Queimado" para o povo Negarotê.

Na década de 1940, no Vale do Juruena, território dos Nambiquara ${ }^{5}$, surgiram seringais próximos às matas dos Rios Piolho, Cabixi, Sabão e Galera. O barracão central, responsável pelo abastecimento de todos os seringais da região, chegou a empregar 200 trabalhadores, sobretudo os indígenas Negarotê (PRICE, 1975). Em entrevista, o ancião Sebastião Negarotê6 relata que, por volta da década de 1960, após o final do expediente, mulheres indígenas Negarotê retornaram às aldeias com os canecos de alumínio utilizados para coletar o látex na sangria das árvores. Isso foi considerado um agravo pelo gerente do barracão, chamado Geraldo; como forma de puni-las pela "indisciplina", no dia seguinte, quando as indígenas retornaram ao trabalho no barracão, o gerente e outros seringueiros promoveram o estupro coletivo das mulheres; até mesmo crianças foram sexualmente abusadas. Como desdobramento do ocorrido, os seringueiros saquearam o armazém do barracão; diante do cenário caótico, Geraldo ateou fogo ao barracão e responsabilizou os Negarotê. Em seguida e, possivelmente, temendo a represália dos Negarotê, Geraldo organizou uma expedição e atacou as aldeias, executando todos os indígenas que encontrou. O episódio transforma-se em lugar da memória do povo Negarotê; fundou-se, no local do acontecimento, a Aldeia Barracão Queimado.

\footnotetext{
${ }^{5}$ Os Negarotê fazem parte dos Nambiquara da Serra do Norte, que são compostos, ainda, pelos grupos Sabanê, Tawanté, Lacondê, Idalamerê, Mamaindê, Latundê e Nesu (Manduca).

${ }^{6}$ Destacamos e agradecemos o auxílio do acadêmico Mauyrio Negarotê na tradução da entrevista.
} 
No final da década de 1960, o preço da borracha passou por forte desvalorização; como forma de compensar os seringalistas, o governo do estado de Mato Grosso ${ }^{7}$ concedeu-lhes a titulação das terras dos seringais - muitas dessas terras estavam dentro do território dos índios Nambiquara. Com a posse do título, os seringalistas venderam as terras aos pecuaristas, iniciando um novo ciclo de luta pelo reconhecimento das terras e dos direitos dos povos Nambiquara. A demarcação das Terras Indígenas Nambiquara ocorreu somente em 1990, por meio do Decreto ${ }^{\circ} 98.814$.

\section{CONSIDERAÇÕES FINAIS}

A exploração da força de trabalho indígena nos seringais foi apenas uma pequena parte de um processo complexo de expansão das relações capitalistas rumo às fronteiras amazônicas. A luta dos povos indígenas não começou em 1988, com a Constituição Federal, bem como está longe de ter um fim. Não se nega o avanço democrático representado pelo artigo 231 da Carta Magna, que teve a sensibilidade de incorporar reivindicações históricas das lutas indígenas e assegurar $13 \%$ do território nacional - a maior parte localizado na chamada Amazônia Legal - como reservas indígenas demarcadas e homologadas. Entretanto, atualmente, os povos indígenas vivem num clima de suspensão, com seus direitos em constante ataque. Estamos diante de uma disputa entre projetos de sociedade, em que os direitos sociais - não apenas dos indígenas, mas de todos os brasileiros - estão em xeque; especificamente as populações indígenas, em Rondônia, enfrentam o desafio de preservar seu território, constantemente ameaçado por madeireiros, empreendimentos do agronegócio e, mais recentemente, pelo setor energético, com a construção das PCHs.

\section{REFERÊNCIAS}

AQUINO, Terri Valle. 1985. Os Kaxarari. Relatório de avaliação, CPI-Acre.

BRASIL. Instituto Brasileiro do Meio Ambiente - "Relatório do Monitoramento do Desmatamento nos Biomas Brasileiros por Satélite”. IBAMA/CSR. Disponível

\footnotetext{
${ }^{7}$ Antes da criação do estado de Rondônia, em 1981, parte significativa de seu território pertencia ao estado de Mato Grosso.
} 
em: $<$ http://www.mma.gov.br/estruturas/sbf_chm_rbbio/_arquivos/relatoriofinal_cerrado_201 0_final_72_1.pdf $>$. (Acessado em 29 de julho de 2017).

CAMARGO, Felisberto C. 1943. Considerações relativas ao problema de formação de seringais na Amazônia. Belém, Instituto Agronômico do Norte. (Circular n. 1).

CARRERA, Nicolás Iñigo. 1988. "La violencia como potencia económica: Chaco 18701940". In: Conflictos y Procesos de la Historia Contemporánea Argentina. CEAL, Buenos Aires, n. 11.

CASPAR, Franz. 1958. Tuparí: entre os índios, nas florestas brasileiras. São Paulo, Melhoramentos.

CASTRO, Maria Inês Malta. 1993. O preço do progresso: a construção da Estrada de Ferro Noroeste do Brasil (1905-1914). Dissertação de Mestrado em História, Universidade Estadual de Campinas.

COMTE, Augusto. 1978. Curso de Filosofia Positiva. São Paulo, Abril Cultural. (Coleção: Os Pensadores).

ELIAS, Norbert. 1994. O processo civilizador: uma história dos costumes. Rio de Janeiro, Zahar (v.1).

FONSECA, Dante Ribeiro da; TEIXEIRA, Marcos Antonio Domingues. 2003. História Regional (Rondônia). Porto Velho, Rondonia.

FUNAI. 1997. Relatório de viagem à Área Indígena Kaxarari.

HOBSBAWM, Eric J. 1984. A Era das Revoluções (1789-1848). 7. ed. Rio de Janeiro, Paz e Terra.

1998. A Era dos Impérios. Rio de Janeiro, Paz e Terra.

HOLANDA, Sérgio Buarque de. 1991. Raízes do Brasil. Rio de Janeiro, José Olympio.

INPE \& EMBRAPA: Instituto Nacional de Pesquisas Espaciais e Empresa Brasileira de Pesquisa Agropecuária. Levantamento de informações de uso e cobertura da terra na Amazônia, 2017. (Acessado In: http://www.inpe.br /cra/projetos_pesquisas/terraclass.php em 05 de junho de 2017).

IZIDORO, Edinéia Aparecida. 2006. Situação sociolingüística do povo Arara: uma história de luta e resistência. Dissertação de Mestrado em Letras, Universidade Federal de Goiás.

KOHLHEPP, Gerd. 2002. "Conflitos de interesse no ordenamento territorial da Amazônia brasileira.” Estudos Avançados. São Paulo, 16 (45).

LAGOS, Marcelo. 1999/2000. "Problemática del aborigen chaqueño. El discurso de la “integración” 1870-1920”. Travesía, Buenos Aires, 3: 69-98. 
MALDI, Denise. 1991. "O complexo cultural do Marico: sociedades indígenas dos rios Branco, Colorado e Mequens, afluentes do Médio Guaporé". Boletim do MPEG, Antropologia, Belém, 7 (2): 209-69.

1984. Populações indígenas e a ocupação histórica de Rondônia. Cuiabá, Universidade Federal de Mato Grosso.

MARTINS, José de Souza. 1979. O cativeiro da Terra. São Paulo, Livraria Editora Ciências Humanas.

MEDEIROS FILHO, João; SOUZA, Itamar. 1984. Os Degredados Filhos da Seca. Petrópolis, Vozes.

MEDEIROS, Edilson Lucas. 2003. Rondônia Terra dos Karipunas. Porto Velho, Rondoforms.

MORAES, Antonio Carlos Robert. 2003. “O Sertão: um 'outro' geográfico”. Terra Brasilis, Rio de Janeiro, 3-4 (4-5): 11-23.

NEVES, Josélia Gomes. 2006. Em defesa do Rio Machado e sua gente, os índios da etnia Arara e Gavião avisam: não queremos barragens. Relatório de Atividades de Extensão Universitária, Ji-Paraná, Universidade Federal de Rondônia.

OLIVEIRA FILHO, João Pacheco. 1979. "O caboclo e o brabo: notas sobre duas modalidades de força de trabalho na expansão da fronteira amazônica do século XIX”. In: SILVEIRA, E. (Org.). Encontros com a civilização brasileira. Rio de Janeiro, Civilização Brasileira.

PEREIRA, Jomar da Paes et al. 2000. Cadeia produtiva da borracha natural: análise diagnóstica e demandas atuais no Paraná. Londrina, Instituto Agronômico do Paraná.

PIZARRO, Ana. 1994. América Latina: Palavra, Literatura e Cultura: A emancipação do discurso. Campinas, Universidade Estadual de Campinas,v.2.

POLANCO, Héctor Díaz. 1995. Etnia y nación en América Latina. Ciudad do México, Consejo Nacional para la Cultura y las Artes.

PRICE, Paul David. 1975. "Política indigenista e política indígena entre os Nambiquara". Informativo FUNAI, ano V (15/16).

RENSHAW, John. 2006. "A 'eficácia simbólica' revisitada: cantos de cura ayoreo”. Rev. Antropol. [online], 49 (1): 393-427.

SAID, E. W. 1995. Cultura e Imperialismo. São Paulo, Companhia das Letras.

SANTOS, Edna Dias dos. 2002. “Os Kaxarari”. In: Povos do Acre: História indígena da Amazônia Ocidental. Rio Branco, Fundação de Cultura e Comunicação Elias Mansour; Conselho Indigenista Missionário. 
SCHWARCZ, Lilia K. Moritz. 1993. O Espetáculo das Raças - cientistas, instituições e questão racial no Brasil 1870-1930. São Paulo, Companhia das Letras.

SEDAM (Secretaria de Estado de Desenvolvimento Ambiental de Rondônia). 2002. Atlas Geoambiental de Rondônia. Porto Velho.

SOUZA, Candice Vidal. 1997. A Pátria Geográfica. Sertão e litoral no pensamento social brasileiro. Goiânia.

SOUZA, Itamar. 1978. Migrações Internas no Brasil. Dissertação de Mestrado, Universidade de São Paulo.

VOORT, Hein van der. 2007. "Proto-Jabutí: Um primeiro passo na reconstrução da língua ancestral dos Arikapú e Djeoromitxí". In: Boletim do Museu Paraense Emílio Goeldi (Ciências Humanas).

WIEVIORKA, Michel. 2004. Mémoire, identité et histoire. Pour (181).

WOLLFF, Cristina Scheibe. 1999. Mulheres da Floresta: uma história: Alto Juruá, Acre (1890-1945). São Paulo, Hucitec.

WRIGHT, Pablo G. 1997. El desierto del Chaco: geografías de la alteridad y el estado. In: TERUEL, Ana; JEREZ, Omar (Comp.). Pasado y presente de un mundo postergado: estudios de antropología, historia y arqueología del Chaco y Pedemonte Surandino. Jujuy, Universidad Nacional de Jujuy. 